\title{
Comparação entre dois protocolos para obtenção de plasma rico em plaquetas, em cães
}

[Comparison between two protocols to obtain platelet-rich plasma in dogs]

\author{
G.A.S. Aleixo ${ }^{1}$, M.C.O.C. Coelho ${ }^{1}$, M.N. Teixeira ${ }^{1}$, E.P. Mesquita ${ }^{1}$, F.F. Oliveira ${ }^{1}$, L.M.V. Zubieta ${ }^{1}$, \\ T.L.C. Almeida ${ }^{1}$, A.L.N. Guimarães ${ }^{1}$, F.C. Maia ${ }^{1}$, T.F.L. Zacarias ${ }^{1}$, \\ S.M.L.G. Santos ${ }^{1}$, C.P.S. Lima $^{2}$
}

\author{
${ }^{1}$ Departamento de Medicina Veterinária - Universidade Federal Rural de Pernambuco \\ Rua Dom Manoel de Medeiros, s/n, Dois Irmãos \\ 52171-900 - Recife, PE \\ ${ }^{2}$ Médico veterinário autônomo
}

\begin{abstract}
RESUMO
Avaliaram-se dois protocolos para a produção de plasma rico em plaquetas (PRP) com o sangue de 20 cães adultos. Foram coletados três frascos de sangue em que um deles foi usado para produção do PRP por meio do protocolo A - centrifugação única a 1200rpm/10min -, o outro para fabricação do PRP pelo protocolo B - primeira centrifugação a 1200rpm/10min e a segunda centrifugação a 1600rpm/10min - e o terceiro para realização da contagem plaquetária no sangue total, que serviu de parâmetro para os valores alcançados no PRP. O protocolo no qual foi possível alcançar maior concentração plaquetária foi testado em outros 20 cães para avaliar sua reprodutibilidade. Constatou-se que o protocolo B resultou em maior plaquetometria em $100 \%$ das amostras e concluiu-se ser ele eficiente para a produção do PRP em cães.
\end{abstract}

Palavras-chave: cão, fatores de crescimento, gel de plaquetas

\begin{abstract}
The objective of this paper was to analyze two protocols for the production of platelet rich plasma (PRP) in dogs. Peripheral blood of 20 adult dogs was collected into three tubes. The first was processed through protocol A - single centrifugation at 1200rpm for 10min -, the second was submitted to protocol B - a first centrifugation at 1200rpm for 10min and a second centrifugation at 1600rpm for 10min -and the third was used to perform platelet count in whole blood, which served as a parameter for values obtained in PRP. The protocol in which it was possible to achieve a higher platelet count was tested in other 20 dogs to evaluate its reproducibility. Protocol B resulted in a superior platelet count in $100 \%$ of the samples, concluding that the referred protocol is effective for PRP production in dogs.
\end{abstract}

Keywords: dog, growth factors, platelet gel

\section{INTRODUÇÃO}

A importância em aumentar a quantidade de plaquetas está no fato de que os $\alpha$-grânulos localizados no seu interior sintetizam e liberam fatores de crescimento (FC), quando as plaquetas são ativadas (Marx, 2004; Bolta, 2007). Os FC são moléculas bioativas fundamentais para o processo de reparação tecidual, pois são capazes de estimular a mitogênese, angiogênese, quimiotaxia e diferenciação celular (Sánchez et al., 2003).
Atualmente, tem-se dado muita ênfase ao emprego de um produto proveniente do sangue do próprio paciente, chamado de plasma rico em plaquetas (PRP). Este é fabricado por um processo que consiste na centrifugação do sangue, com o objetivo de concentrar maior quantidade de plaquetas no menor volume de plasma (Marx, 2001; Floryan e Berghoff, 2004; Pagliosa e Alves, 2007; Whitlow et al., 2008).

Existem relatos do uso do PRP em cirurgias odontológicas, ortopédicas, oftálmicas,

Recebido em 13 de março de 2010

Aceito em 6 de abril de 2011

E-mail: grazielle@yahoo.com 
neurológicas, laparoscópicas, reconstrutivas, entre outras. Embora haja grande evidência sobre os benefícios do seu uso como promotor da reparação tecidual, até o momento não existe um único protocolo estabelecido para sua produção, ficando, em geral, a critério de cada pesquisador estabelecer uma metodologia própria que possa ser exequível diante das condições de trabalho existentes.

Nas primeiras tentativas de produção, eram utilizados grandes equipamentos de autotransfusão (Jameson, 2007), entretanto era preciso colher volumosas amostras de sangue aproximadamente $500 \mathrm{~mL}$ - e ter a presença de um profissional experiente para realizar tal procedimento (Vendramin et al., 2006). Com o passar dos anos, desenvolveram-se equipamentos automáticos menos sofisticados (Roukis et al., 2006), porém ainda de custo elevado, tornando o seu emprego restrito (Rossi Júnior e Souza Filho, 2004). Com a finalidade de reduzir gastos, outros protocolos foram criados utilizando-se centrífugas convencionais (Efeoglu et al., 2004), embora muitas vezes o processo tenha sido árduo e tenha sido exigida a presença de um profissional experiente com a técnica empregada (Vendramin et al., 2006).

Independentemente do protocolo utilizado, é recomendado que ele seja capaz de aumentar a contagem plaquetária em uma concentração bem acima da encontrada no sangue total, desde que sejam preservadas a estrutura e a função das plaquetas, pois, de acordo com Lopez et al. (2007), se as plaquetas se romperem liberando os FC antecipadamente, a ação terapêutica do PRP será prejudicada.

Este trabalho teve o objetivo de estabelecer um protocolo eficiente para a obtenção do PRP em cães por meio da análise comparativa entre dois métodos.

\section{MATERIAL E MÉTODOS}

Durante a primeira etapa da pesquisa, foram coletadas amostras de sangue de 20 cães adultos, machos (nove) e fêmeas (11), entre dois e cinco anos de idade e com pesos variando de 10 a 20kg. O experimento foi autorizado pela Licença $n^{\circ}$ 019/2009, concedida pela Comissão de Ética no Uso de Animais da UFRPE. A coleta de sangue foi realizada a vácuo, com agulha calibre 25x7mm (Agulha de coleta múltipla preta Vacuette do Brasil, Americana/SP). Colheramse, de cada paciente, dois frascos de sangue de 4,5mL contendo citrato de sódio (Tubos de coleta a vácuo com citrato de sódio a 3,2\% Labor Import, Osasco/SP) e um outro, de $2 \mathrm{~mL}$, contendo EDTA (Tubo de coleta a vácuo com EDTA Vacuette ${ }^{\circledR}$ - Vacuette do Brasil, Americana/SP).

O primeiro frasco, com citrato de sódio, foi empregado na produção do PRP pelo protocolo A e constou de uma única centrifugação a 1200 rotações por minuto (rpm) durante 10 minutos, em centrífuga laboratorial (Centrífuga de Bancada Baby ${ }^{\circledR}$ I Modelo 206 bl - Fanem ${ }^{\circledR}$, Guarulhos/SP). Posteriormente à primeira centrifugação, o tubo apresentava três camadas distintas formadas pelas hemácias - fundo do tubo -, pela zona de névoa, composta pelos leucócitos e plaquetas maiores - camada intermediária - e pelo plasma - camada superior. Da parte mais superficial do plasma descartaramse cerca de $80 \%$, com um pipetador automático (Pipetador automático - Kacil Indústria e Comércio Ltda., Recife/PE) e uma ponteira estéril (Ponteira tipo Gilson para pipeta automática - Cral Artigos para Laboratório Ltda., Cotia/SP). O restante, correspondente à porção mais concentrada em plaquetas, e a camada leucoplaquetária foram pipetados para serem acondicionados em um frasco estéril de $3 \mathrm{~mL}$, sem aditivo (Tubo de coleta a vácuo sem aditivo Vacuette $^{\circledR}$ - Vacuette do Brasil, Americana/SP).

O segundo frasco com citrato de sódio foi submetido ao protocolo $\mathrm{B}$, em que, após a primeira centrifugação a 1200rpm por 10 minutos, todo o plasma e a zona de névoa foram aspirados, transferidos para um tubo estéril sem aditivo e centrifugados pela segunda vez, agora a 1600rpm por 10 minutos. Em seguida, descartaram-se aproximadamente $80 \%$ do sobrenadante com um pipetador automático, permanecendo apenas a parte mais concentrada em plaquetas e o botão plaquetário que se encontrava no fundo do tubo. A plaquetometria do plasma contido nos tubos dos protocolos A e $B$ foi realizada pelo método de contagem direta descrita por Coles (1984), utilizando-se o diluente de Rees-Ecker. 
No sangue colhido no frasco com EDTA, realizaram-se o hemograma e a plaquetometria para avaliar o estado de saúde geral dos animais e obter os valores de referência para as plaquetas no sangue total. A plaquetometria foi realizada pelo método direto, por meio da contagem em câmara de Neubauer, como descrito para a contagem no PRP.

Para verificar a suficiência amostral, considerouse o processo inteiramente aleatório com erro previsto de $10 \%$. A quantidade de plaquetas alcançadas em cada protocolo e o valor basal (de referência) foram analisados segundo delineamento inteiramente ao acaso, com três tratamentos e 20 repetições. Para comparação de médias, usou-se o teste Tukey, a $1 \%$ de probabilidade (Silva e Silva, 1999).

Após a definição do protocolo no qual se alcançou maior número de plaquetas no PRP - Protocolo B -, foram obtidas novas amostras, colhidas em outros 20 cães com o mesmo padrão de peso e idade, para avaliar o seu índice de reprodutibilidade. Foi apresentada a estatística descritiva e observou-se o comportamento dos limites de confiança de cada grupo. A análise qualitativa do PRP obtido pelo protocolo B foi efetuada pela observação da coagulação do produto após a adição de tromboplastina (Tempo de Protrombina (TP) - Laborlab, Guarulhos/SP), na proporção de 2:1 (PRP:tromboplastina) em uma amostragem de 10 animais, escolhidos ao acaso e mediante avaliação morfológica das plaquetas em esfregaço sanguíneo.

\section{RESULTADOS E DISCUSSÃO}

No presente experimento, o cálculo do tamanho da amostra indicou que seriam necessários 13,26 animais - no caso 14 - com um erro real de amostragem de 8,2\%. Como foram utilizados 20 animais e o erro foi menor que o máximo adotado (10\%), o número de pacientes foi considerado suficiente. Em três dos 20 animais (números 7, 15 e 20), não foi atingido o valor de 1.000 .000 plaquetas/ $\mu \mathrm{L}$ em ambos os protocolos (Fig. 1), o que, segundo Marx (2004), é o valor estipulado para que se atinja a ação terapêutica do PRP. Em dois animais (números 15 e 20), a contagem de plaquetas ficou abaixo de $900.000 / \mu \mathrm{L}$, porém ainda foi possível incrementar a contagem plaquetária desses pacientes em cinco vezes em relação ao valor basal. Esse autor recomendou que o incremento na plaquetometria do PRP seja de quatro a cinco vezes, portanto estes também podem ser considerados PRP.

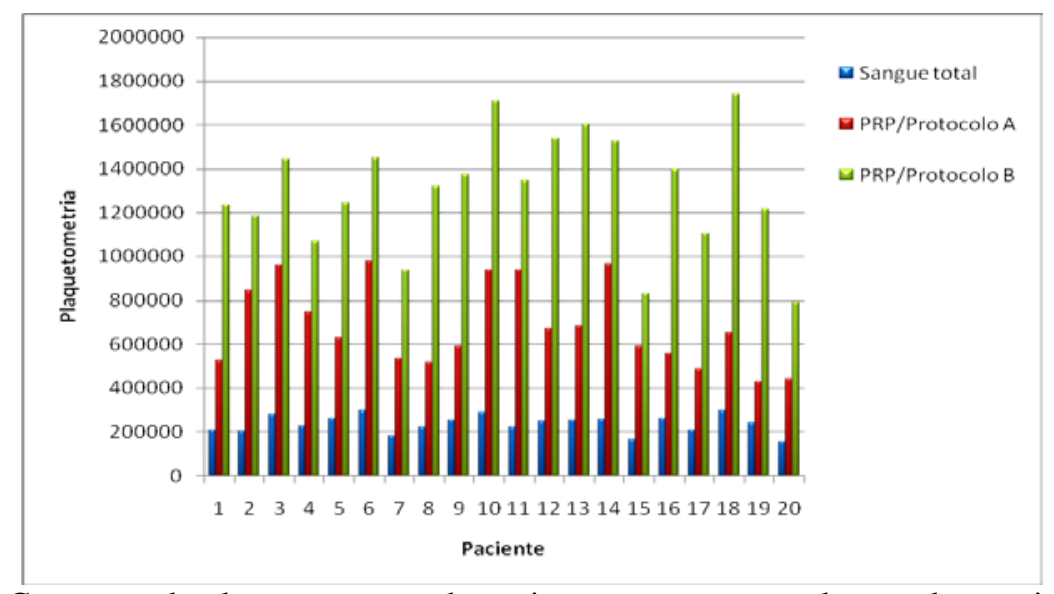

Figura 1. Cão. Contagem de plaquetas, em cada paciente, no sangue total e no plasma rico em plaquetas (PRP) obtido pelos protocolos A (1200rpm/10min) e B (1200rpm/10min e 1600rpm/10min).

O fato de não se ter atingido 1.000 .000 plaquetas/ $\mu \mathrm{L}$ nos três animais citados se justifica em razão de eles terem apresentado contagem plaquetária mais baixa que o valor de referência para a espécie canina no sangue basal. Conforme Floryan e Berghoff (2004), animais trombocitopênicos não devem ser usados para a produção do PRP, pois o valor da plaquetometria neles está diretamente relacionado à contagem no sangue total (Barbosa et al., 2008). Os resultados aqui observados confirmaram essa recomendação. 
O PRP tem sido bastante difundido por causa das diversas aplicações clínicas a ele relacionadas. Muitos protocolos foram descritos e recomendados, mas não há uma padronização de seu processamento. A comparação entre o protocolo de centrifugação única e de duas centrifugações neste experimento fundamentouse no fato de alguns autores (Green e Klink, 1998; Nunes Filho et al., 2007; Messora et al., 2008) recomendarem a primeira técnica, enquanto outros (Sonnleitner et al., 2000; Ossa e Orrego, 2004; Silva et al., 2009) indicaram a segunda.

Para a centrifugação do plasma, optou-se pelo uso de 1200 e $1600 \mathrm{rpm}$, por serem essas rotações executáveis na centrífuga utilizada e por estarem dentro da média estabelecida em outros trabalhos, apesar de não terem sido encontrados artigos com a combinação dessas mesmas velocidades. O aumento na velocidade de rotação na segunda centrifugação para 1600rpm correspondeu ao aumento da capacidade da centrífuga utilizada, em que cada aumento de graduação equivale a 400rpm. O aumento da velocidade de centrifugação no segundo processo, empregado nos trabalhos de Aghallo et al. (2002), Scarso Filho (2002) e Ferraz et al. (2007), baseou-se no fato de que uma segunda rotação, de maior intensidade, permitiria separar melhor a fração do plasma pobre em plaquetas que corresponde à parte superior -, da parte inferior - que representa o PRP (Barroso et al., 2007).

Não foram escolhidas centrifugações mais altas do que $1600 \mathrm{rpm}$, como as realizadas por Ferraz et al. (2007), em que também foram testadas 3200rpm, pois Adler e Kent (2002) relataram que a velocidade de centrifugação excessiva pode danificar as plaquetas e resultar em um PRP de má qualidade. Os resultados alcançados por Ferraz et al. (2007) demonstraram que o emprego de 3200rpm na segunda centrifugação concentrou maior quantidade de plaquetas, mas estas se encontravam morfologicamente alteradas, interferindo na qualidade do produto.

Diversas causas podem resultar em trombocitopenias, como a hipoplasia medular (induzida por fármacos), as doenças infecciosas (erliquiose), a trombocitopenia imunomediada, a coagulação intravascular disseminada (Rebar et al., 2003), a doença esplênica, a endotoxemia e a deficiência nutricional severa (Walker, 2009). Entre as causas citadas, merece relevância a trombocitopenia causada pela Ehrlichia sp, especialmente com relação à Anaplasma platys, cuja célula-alvo é a plaqueta, pois o número de casos suspeitos de infecção por essa bactéria vem aumentando consideravelmente (Paz e Silva et al., 2009). Mais especificamente com relação à cidade do Recife, onde este experimento foi executado, uma pesquisa realizada por Teixeira et al. (2002), com cães naturalmente infectados por Anaplasma platys, constatou que o sinal laboratorial mais frequentemente observado nos animais foi a trombocitopenia (79\%).

Os resultados da plaquetometria encontram-se na Tab. 1.

Tabela 1. Resultados de plaquetometria realizada em cães, segundo os protocolos

\begin{tabular}{lll}
\hline Tratamento & Média & \\
\hline PRP/Protocolo B & 1303000 & A \\
PRP/Protocolo A & 683000 & B \\
Sangue total & 236750 & C \\
\hline
\end{tabular}

Letras distintas na coluna indicam diferenças entre protocolos, pelo teste Tukey.

As três contagens foram diferentes entre si. O protocolo B foi o mais eficiente por concentrar maior número de plaquetas por animal analisado. Em termos percentuais, o protocolo B alcançou 90,8\% mais plaquetas que o protocolo A. Para confirmar a eficiência do protocolo B, aplicou-se o método em outros 20 animais para observar a reprodutibilidade dele (Tab. 2).

Tabela 2. Contagem de plaquetas no protocolo B em animais da primeira (EI) e da segunda etapa (EII) para avaliar a reprodutibilidade do método

\begin{tabular}{lcc}
\hline Estatísticas & EI & EII \\
\hline Número de animais & 20 & 20 \\
Média & 5,489 & 5,374 \\
Limite superior* & 5,805 & 5,786 \\
Limite inferior* & 5,174 & 4,962 \\
\hline
\end{tabular}

* 99\% de confiabilidade. 
As plaquetometrias do protocolo $\mathrm{B}$, nos primeiros 20 e nos outros 20 animais usados para verificar a estabilidade do método e de treinamento e eficiência da equipe, apresentaram resultados muito próximos e com limites de confiança cruzando entre si, o que demonstra que o procedimento se repetiu no EII. Resultados semelhantes foram alcançados por Vendramin et al. (2006), nos quais o concentrado de plaquetas produzido após a definição de um protocolo foi reproduzível em todos os outros 10 testes realizados com essa finalidade.

A observação morfológica das plaquetas do PRP em esfregaço sanguíneo não revelou nenhuma alteração. É recomendada como técnica para avaliar a qualidade do produto, pois, quando as plaquetas estão ativadas, elas mudam de forma, passando a apresentar pseudópodos citoplasmáticos (Rebar et al., 2003). A ativação plaquetária durante o processamento do PRP pode antecipar a liberação dos FC pelos grânulos, resultando em perdas deles no plasma (Eppley et al., 2004).

Na avaliação qualitativa do PRP produzido pelo protocolo $\mathrm{B}$ usando $\mathrm{o}$ teste de agregação plaquetária, e aproximadamente seis segundos após a adição do reativo agonista, foi observada a formação de gel de plaquetas. Procedimento semelhante foi verificado por Barroso et al. (2007), no qual a avaliação da função plaquetária foi desempenhada pela ativação do PRP depois da adição de trombina e da formação do coágulo em oito amostras de um total de 45 pacientes. O material pode ser submetido à citometria de fluxo, e foi o que fizeram Barroso et al. (2007), porém, de acordo com Landi e Marques Júnior (2003), a necessidade de mão de obra especializada e do citômetro de fluxo limita o emprego dessa técnica.

Deu-se preferência ao uso da tromboplastina por ser citada na literatura como uma das opções disponíveis para promover a ativação plaquetária e pelos resultados pré-experimentais favoráveis quando de seu emprego. Barbosa et al. (2008) também trabalharam com a tromboplastina, justificando que a trombina bovina não é facilmente encontrada no Brasil. Além disso, de acordo com Vendramin et al. (2006), quando se utiliza a trombina autóloga, a sua concentração deve ser medida por ensaio de atividade amidolítica. O fato de ser necessário quantificar a trombina e dispor de equipamentos e material específico para isso, o que resulta em maior custo de produção e de etapas extras necessárias para a sua fabricação, desencoraja o seu uso.

\section{CONCLUSÕES}

O protocolo de obtenção do plasma rico em plaquetas constituído de duas centrifugações, a primeira a 1200 e a segunda a 1600rpm por 10 minutos cada ciclo, propicia maior concentração plaquetária quando comparado ao protocolo de centrifugação única a 1200rpm por 10 minutos, por isso é efetivo para a produção do PRP em cães.

\section{AGRADECIMENTOS}

Ao CNPq, pelo incentivo ao desenvolvimento da pesquisa, e aos professores Dr. Jean Carlos Ramos e Dra. Andréa Paiva Botelho Lapenda de Moura, da UFRPE, pelo fornecimento de equipamentos necessários para a sua execução.

\section{REFERÊNCIAS BIBLIOGRÁFICAS}

ADLER, S.C.; KENT, K.J. Enhancing wound healing with growth factors. Facial Plast. Surg. Clin. N. Am., v.10, p.129-146, 2002.

AGHALLO, T.L; MOY, P.K; FREYMILLER, E.G. Investigation of platelet-rich plasma in rabbit cranial defects. A pilot study. J. Oral Maxillofac. Surg., v.60, p.1176-81, 2002.

BARBOSA, A.L.T.; DEL CARLO, R.J.; GOMES, H.C. et al. Plasma rico em plaquetas para reparação de falhas ósseas em cães. Cienc. Rural, v.38, p.1335-1340, 2008.

BARROSO, C.S.T.; BENITO, J.C.; PUIG, A.G. Calidad del plasma rico en plaquetas: estúdio de la activación plaquetaria. Rev. Esp. Cir. Oral Maxilofac., v.29, p.240-248, 2007.

BOLTA, P.R.Z. Use of platelet growth factors in treating wounds and soft-tissue injuries. Acta Dermatoven. APA, v.16, p.156- 165, 2007.

COLES, E.H. Hemostasia e coagulação sanguínea. In: Patologia clínica veterinária. 3.ed. São Paulo: Manole, 1984. Cap. 5, p.144-163. 
EFEOGLU, C.; AKCAY, Y.D.; ERTURK, S. A modified method for preparing platelet-rich plasma: An experimental study. J. Oral Maxillofac. Surg., v.62, p.1403-1407, 2004. EPPLEY, B.L.; WOODELL, J.E.; HIGGINS, J.B.S. Platelet quantification and growth factor analysis from platelet-rich plasma: implications for wound healing. Plast. Reconstr. Surg., v.114, p.1502-1508, 2004.

FERRAZ， V.C.M.; FERRIGNO， C.R.A.; SCHMAEDECKE, A. Platelet concentration of plateletrich plasma from dogs, obtained through three centrifugation speeds. Braz. J. Vet. Res. Anim. Sci., v.44, p.435-440, 2007.

FLORYAN, K.M.; BERGHOFF, W.J. Intraoperative use of autologous platelet-rich and platelet-poor plasma for orthopedic surgery patients. Association of perioperative Registered Nurses (AORNJ), v.80, p.668-674, 2004.

GREEN, D.; KLINK, B. Platelet gel as an intraoperatively procured platelet-based alternative to fibrin glue. Plast. Reconstr. Surg, v.101, p.1161-1162, 1998.

JAMESON, C.A. Autologous platelet concentrate for the production of platelet gel. Lab. Med., v.38, p.39- 42, 2007.

LANDI, E.P.; MARQUES JÚNIOR, J.F.C. Caracterização da ativação plaquetária nos concentrados de plaquetas por citometria de fluxo. Rev. Bras. Hematol. Hemoter., v.25, p.3946, 2003.

LOPEZ, J.L.; CHIMENOS, E.; SANCHEZ, J.M. et al. Plasma rico en factores de crecimiento y regeneración ósea. Dentum, v.7, p.108-112, 2007.

MARX, R. Platelet-rich plasma (PRP): what is PRP and what is not PRP? Implant Dent., v.10, p.225-228, 2001.

MARX, R.E. Platelet-rich plasm: evidence to support its use. J. Oral Maxillofac. Surg., v.62, p.489-496, 2004.

MESSORA, M.R.; NAGATA, M.J.H.; OLIVEIRA, G.C.V. et al. Influência do plasma rico em plaquetas (PRP) na cicatrização de defeitos mandibulares tratados com enxerto ósseo alógeno. Estudo radiográfico em cães. In: CONGRESSO BRASILEIRO DE CIRURGIA e ANESTESIOLOGIA VETERINÁRIA, 8., 2008, Recife. Anais... Recife CBCAV, 2008.
NUNES FILHO, D.P.; LUPPINO, F.; YAEDÚ, R.Y.F. et al. Avaliação microscópica da ação do osso autógeno associado ou não ao PRP em cavidades ósseas de cães. Rev. Implant., v.4, p. 263-269, 2007.

OSSA, S.G.; ORREGO, G.E.O. Plasma rico en plaquetas: Una alternativa para acelerar el proceso de cicatrización ósea. Rev. CES Odontol., v.17, p.71-74, 2004.

PAGLIOSA, G.M.; ALVES, G.E.S. Considerações sobre a obtenção e o uso do plasma rico em plaquetas e das células mesenquimais indiferenciadas em enxertos ósseos. Cienc. Rural, v.37, p.1202-1205, 2007.

PAZ E SILVA, F.M.; TEIXEIRA, M.N.; LOPES, R.S. et al. Erlichioses. Vet. Zootec., v.16, p.290-302, 2009.

REBAR, A.H.; MacWILLIAMS, P.S.; FELDMAN, B.F. et al. Plaquetas. In: Guia de hematologia para cães e gatos. São Paulo: Roca, 2003. Cap. 10, p. 131-156.

ROSSI JÚNIOR, R.; SOUZA FILHO, M.A.P. Obtenção de trombina autógena: proposta de um protocolo simplificado e de fácil reprodução clínica. Rev. Paul. Odontol., v.26, p.4-9, 2004.

ROUKIS, T.S.; ZGONIS, T.; TIERNAN, B. Autologous platelet-rich plasma for wound and osseous healing: A review of the literature and commercially available products. Adv. Ther., v.23, p.218-237, 2006.

SÁNCHEZ, A.R.; SHERIDAN, P. J.; KUPP, L.I. Is platelet-rich plasma the perfect enhancement factor? A current review. Int. J. Oral Maxillofac. Implants, v.18, p.93-103, 2003.

SCARSO FILHO, J. Avaliação do plasma rico em plaquetas na proliferação celular. Estudo in vitro. 2002. 75f. Tese (Doutorado em Odontologia) - Universidade Federal de Santa Catarina, Florianópolis, SC.

SILVA, I.P.; SILVA, J.A.A. Modelos estatísticos aplicados à pesquisa científica: uma abordagem para profissionais da pesquisa agropecuária. Recife: UFRPE, 1999. 305p.

SILVA, P.S.A.; DEL CARLO, R.J.; SERAKIDES, R. et al. Plasma rico em plaquetas associado ou não ao osso esponjoso autógeno no reparo de falhas ósseas experimentais. Cienc. Rural, v.39, p. 129-134, 2009. 

$\begin{array}{llll}\text { SONNLEITNER, } & \text { D.; HUEMER, } & \text { P.; } \\ \text { SULLIVAN, D. A } & \text { simplified technique } & \text { for }\end{array}$ producing plateletrich plasma and platelet concentrate for intraoral bone grafting techniques: a technical note. Int. J. Oral Maxillofac. Implants, v.15, p.879-882, 2000.

TEIXEIRA, M.N.; OLIVEIRA, J.B.; TAKAHIRA, R.K. et al. Infecção natural por Ehrlichia platys em caninos na cidade do Recife, Estado de Pernambuco. In: CONGRESSO BRASILEIRO DE PARASITOLOGIA, 12., Rio de Janeiro, 2002. Anais..., Rio de Janeiro: Editora, 2002.
VENDRAMIN, F.S.; FRANCO, D.; NOGUEIRA, C.M. et al. Plasma rico em plaquetas e fatores de crescimento: técnica de preparo e utilização em cirurgia plástica. Rev. Col. Bras. Cir., v.33, p.24-28, 2006.

WALKER, D. Esfregaços de sangue periférico. In: COWELL, R.L.; TYLER, R.D.; MEINKOTH, J.H. et al. Diagnóstico citológico e hematologia de cães e gatos. 3.ed. São Paulo: MedVet, 2009. Cap. 26, p. 390-422.

WHITLOW, J.; SHACKELFORD, A.G.; SIEVERT, A.N. et al. Barriers to the acceptance and use of autologous platelet gel. Perfusion, v.23, p.283-289, 2008. 